\title{
Teaching Information Visualization via Creative Design
}

\author{
Bob Spence $^{(\otimes)}$ \\ Department of Electrical and Electronic Engineering, Imperial College London, \\ London SW7 2AZ, UK \\ r.spence@imperial.ac.uk
}

\begin{abstract}
The importance of Information Visualization is reflected in the many courses on that subject taught worldwide. The number of those courses, however, is not of prime importance: what is of real concern is how they are presented, and to whom.
\end{abstract}

\section{Students}

It is my view that education in information visualization is required primarily by two groups of people: those who will become interaction designers and those who will, at some time in their careers, either commission systems with a significant element of visualization or be responsible for evaluating such systems. I happen to teach both types of student: post-Master professional designers at the Technical University of Eindhoven in the Netherlands and first year undergraduates in Information Systems Engineering at Imperial College London. The material that follows represents a personal view, one that will hopefully trigger debate.

\section{Theory or Practice}

It is my strong belief that the best way to become educated in Information Visualization (and human-computer interaction in general) is to do it. For that reason my condition for presenting those courses is that there be no examination paper, favouring as it does those with photographic memories: rather I wish to encourage creativity and design ability. So I ask my students to undertake design exercises (mostly individually and once as a group) and one design critique.

\section{Teaching Environment}

The environment of my teaching of Information Visualization is of great importance to me. I strive for - and largely achieve - a 'studio' environment, first to approximate that of a real design house and, second, to avoid the traditional 'me and them' attitude: I certainly learn from the course as well as teach it. For example, in keeping with a studio environment I ensure that students paste 
their early designs on a wall, provide a one minute explanation and then for two minutes respond to questions from anyone who cares to ask them. In that way they receive instant and valuable feedback. Although perhaps unexpected, sketching on large sheets of paper with thick pens is encouraged to capture design ideas in the early exploration and design stages (Greenberg et al. [3]): the use of laptops at this stage is frowned upon and virtually forbidden.

\section{Content}

My emphasis on design is not at odds with a concern with theory, though it is theory to support design rather than for its own sake that is my concern. However, difficult decisions must be made about the content of a course on Information Visualization: what theory is relevant and the appropriate mix of theory and design. One decision I found easy to make - was the need for clear definitions.

\subsection{Definitions}

A student would surely be surprised, and disappointed in their teacher, if that teacher cannot provide precise definitions for important concepts. My first concern is to provide definitions where possible, even if they may be contentious. For example, the definition of information visualization I have always used is not shared by most leaders in the field. I refer to two respected dictionaries for the following definition:

visualization $(\mathrm{v})$ : the formation of a mental model of something,

with the implication that visualization is a cognitive activity undertaken by a human being and has nothing fundamentally to do with computers. I am pleased that recent publications are recognising the importance of this definition, instead of taking the attitude that the letters $\mathrm{v}-\mathrm{i}-\mathrm{s}-\mathrm{u}-\mathrm{a}-\mathrm{l}$ in the word visualization implies that data can only be encoded graphically. My attitude may seem pedantic, but if we forget what the user is trying to achieve we tread a dangerous path. A visualization is not what we see on a display - it is in the mind.

\subsection{Examples}

In view of the paucity of relevant theory, Information Visualization is largely taught by a critical review of illustrative examples and the discussion of concepts. For example, a student undertaking their first design of a representation (the marks out of ten in 8 subjects taken by 5 students) may be informed by Bertin's [1] work and the concepts of object and attribute visibility [6], but will find that there is no 'algorithm' guaranteed to lead to the 'best' design (there simply isn't one) and that a design's effectiveness depends upon the ultimate user(s) of the representation. 


\subsection{The Human User}

Information Visualization as a discipline acquired a very bad name in its early years by the preponderance of displays that took no account whatsoever of the human user: they were often primarily exercises in programming. I therefore lay considerable stress on the characteristics of the human user, initially by providing actual - and to my students surprising - examples of phenomena such as Change Blindness, Attention Blindness and Preattentive Processing, but these topics are introduced in context rather than being taught within a separate set of lectures. Similarly, I emphasise the importance of considering the human user by ensuring that the first stage of an interaction design (the final group project) is a careful consideration of who the user is and what their goal and modus operandi are. Some students are not aware of the need for this first step and immediately propose, in detail, their 'final' and often impoverished design.

\subsection{Restrictions}

Occasionally the result of a student project identifies an omission in the teaching of Information Visualization. For example, in response to an exercise asking for a proposal for a new kind of family tree - a task conventionally interpreted as requiring a visual display - one group of my students proposed a family tree made of wood: yes, wood. That tree was visually attractive, stood on a table and had embedded communication facilities such that a family member in one part of the world could easily maintain social contact with another member located many miles away, perhaps with a simple touch and the utterance Hi Gran! Examples such as these are a reminder that a (perhaps unconscious) emphasis on computers needs to be guarded against.

\subsection{Interaction}

At an introductory level I try to present information visualization in a structured manner, using the generally accepted though simple model of Fig. 1 to identify the essentials of the subject. I have little problem with the topic of representation, by combining a selection of techniques with concepts such as those due to Bertin [1] and to Teoh and Ma [6]. Equally, many examples can illustrate the topic of presentation in both space (e.g., the distortion concept) and time (e.g., Rapid Serial Visual Presentation) and a combination of the two. It is with the topic of Interaction that a structure seems a little elusive, notwithstanding its immense importance to information visualization. The search for a science of interaction advocated by Thomas and Cook [7] appears to be exceedingly challenging, but interaction in the restricted context of information visualization should surely be achievable and taught at first year level. Consideration of the features of interaction in this context strongly suggests the relevance of Norman's Stages of Action [5], a concept I introduce very early in my courses. After all, we have a clear goal (the enhancement of a mental model of data); we have 'changes in the world' (changes in D, R and P - see Fig. 1); we have the 


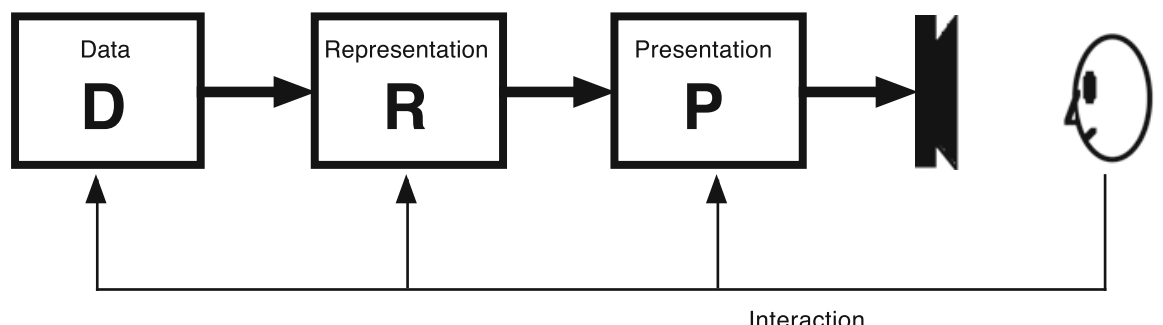

Fig. 1. Model of a system supporting information visualization

ever present requirement to formulate an action plan before interaction takes place (and relevant concepts such as sensitivity and affordance); and we have a multitude of devices permitting execution - the 'action' of 'interaction'. And the discussion provided by Yi et al. [8] may well be related to another component of Norman's Cycle, the formulation of an intention. Consideration of the perception and interpretation following whatever change occurs in the world (often a visual display) can lead to improvements in the interface being designed. The relevance of Norman's Cycle would appear to extend from conventional navigation in discrete information spaces to the extremely rapid cycle of execution-perception-interpretation-execution involved in the rapid dynamic exploration of complex relationships (see, for example, Neufeld et al. [4]).

\section{Visual Analytics}

In the context of information visualization the principal value of the newly defined 'discipline' of Visual Analytics can be summarised in a simple statement: Information Visualization exists in context. Acknowledgement of this obvious fact must exist in any course, but not overwhelm it. Simple examples can often suffice to underline this message: the more complex example provided by Colgan et al. [2] is only one of many that can be drawn from many publications extending over the last two or three decades

\section{Conclusions}

My personal conclusion is that the topic of information visualization is best taught via creative design in a realistic application context.

\section{References}

1. Bertin, J.: (1981) Graphics and graphic information Processing, Berlin, Walter de Gruyter: a translation of La Graphique et le Traitment Graphique de l'Information. Flammarion, Paris (1977) 
2. Colgan, L., Spence, R., Rankin, P.R.: The cockpit metaphor. Behav. Inf. Technol. 14(4), 251-263 (1995)

3. Greenberg, S., Carpendale, S., Marquardt, N., Buxton, B.: Sketching User Experiences. Morgan Kaufmann, Amsterdam (2012)

4. Neufeld, E., Kristtorn, S., Guan, Q., Sanscartier, M., Ware, C.: Exploring causal influences. In: Erbacher, R.F., Roberts, J.C., Grohn, M.T., Borner, K. (eds.) Visualization and Data Analysis, vol. 5669, pp. 52-62. SPIE, San Jose (2005)

5. Norman, D.A.: The Design of Everyday Things. Doubleday, New York (1988)

6. Teoh, S.-T., Ma, K.-L.: 'Hifocon': Object and dimensional coherence and correlation in multidimensional visualization. In: Bebis, G., Boyle, R., Koracin, D., Parvin, B. (eds.) ISVC 2005. LNCS, vol. 3804, pp. 235-242. Springer, Heidelberg (2005)

7. Thomas, J., Cook, K.A.: Illuminating the path. IEEE Computer Society, Los Alamitos (2005)

8. Yi, J.S., Kang, Y.A., Stasko, J.T., Jacko, J.A.: Toward a deeper understanding of the role of interaction in information visualization. IEEE Trans. Vis. Comput. Graph. 13(6), 1224-1231 (2007) 